\title{
Process-oriented statistical-dynamical evaluation of LM precipitation forecasts
}

\author{
A. Claußnitzer, I. Langer, P. Névir, E. Reimer, and U. Cubasch \\ Institut für Meteorologie, Freie Universität Berlin Carl-Heinrich-Becker-Weg 6-10, D-12165 Berlin, Germany \\ Received: 1 August 2007 - Revised: 10 January 2008 - Accepted: 29 February 2008 - Published: 9 April 2008
}

\begin{abstract}
The objective of this study is the scale dependent evaluation of precipitation forecasts of the Lokal-Modell (LM) from the German Weather Service in relation to dynamical and cloud parameters. For this purpose the newly designed Dynamic State Index (DSI) is correlated with clouds and precipitation. The DSI quantitatively describes the deviation and relative distance from a stationary and adiabatic solution of the primitive equations. A case study and statistical analysis of clouds and precipitation demonstrates the availability of the DSI as a dynamical threshold parameter. This confirms the importance of imbalances of the atmospheric flow field, which dynamically induce the generation of rainfall.
\end{abstract}

\section{Introduction}

In the last years the development of numerical weather prediction (NWP) models there has been great progress in the short-term and middle-term forecast of temperature, wind speed or direction and cloud coverage, but only minor success in the quantitative precipitation forecast (QPF). In order to improve the NWP models, it is necessary to understand the precipitation processes. In general, rainfall is a very discontinuous variable in space and time. It is difficult to obtain spatial-temporal information about precipitation on the observational as well as on the modelled basis.

Physically, in the mid-latitudes rainfall develops via the ice phase in the clouds, the so-called Bergeron-FindeisenProcess. In synoptic meteorology, precipitation is linked to upward vertical motion in large-scale baroclinic systems. In particular, in the mid-latitudes high correlations of precipitation rates and vertical velocity can be found (Rose and

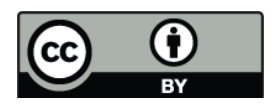

Correspondence to: A. Claußnitzer (antje.claussnitzer@met.fu-berlin.de)
Lin, 2003). Alternatively, the ageostrophic horizontal divergence weighted with the specific humidity is used to estimate diagnostic precipitation rates (Spar, 1953; Palmén and Holopainen, 1962; Banacos and Schultz, 2005). Other research groups deal with the statistical analysis of precipitation processes to investigate a multifractal (e.g. Olsson et al. , 1993; Tessier et al., 1993; Lovejoy and Schertzer, 1995) and a chaotic behaviour (Rodriguez-Iturbe et al., 1989; Sivakumar, 2001). In particular, there is an indication that convective precipitation is linked to self-organised critical phenomena, with the saturation of water vapour as the dynamical threshold (Peters and Christensen, 2006). A previous study from Langer and Reimer (2007) shows an improvement by considering the clouds types derived from Meteosat-7 for an independent numerical interpolation procedure to build up an observational precipitation analysis in a resolution corresponding to the LM grid (Reimer and Scherer, 1992).

The aim of this paper is to present a connection between the Dynamic State Index (DSI), which skillfully combines the above-mentioned imbalances of the flow fields, and precipitation as well as clouds. The paper is divided into the following parts: Sect. 2 gives a short description of the DSI and Sect. 3 specifies the Meteosat- 8 channels and the derived cloud types. The data sets used as well as the calculation of the DSI and cloud types are presented in Sect. 4. The results of this study are given in Sect. 5, organised in three themes. First the correlation between the DSI and the precipitation derived from the LM data is presented, then a case study shows the exceeding agreement in space. In the last subsection Meteosat- 8 data are used and with a new approach the precipitation activity of different cloud types is calculated. Finally Sect. 6 gives a summary.

Published by Copernicus Publications on behalf of the European Geosciences Union. 

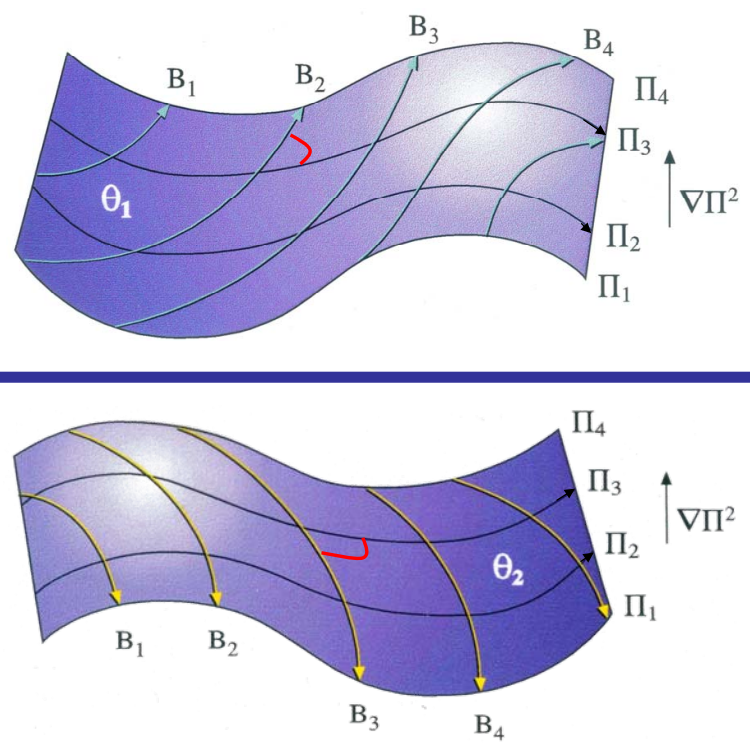

Fig. 1. Isolines of $\Pi$ and Bernoulli-stream function on two different isentropic levels $\theta_{1}$ and $\theta_{2}$. The red lines indicate angles between Bernoulli streamfunctions and PV isolines with $\Pi_{4}>\Pi_{1}$.

\section{Dynamic State Index DSI}

Usually, precipitation is a parameter, which is linked to changes in the atmospheric circulation, e.g. growth of baroclinic waves and frontogenesis on the synoptic scale. It is also coupled with the mesoscale convective system (e.g. Houze, 2004). These meteorological phenomena can be attributed to non-balanced processes. The newly designed Dynamic State Index (DSI) describes the deviation from the stationary solution of the adiabatic primitive equations (Névir, 2004) and is in this way a measure of non-balanced properties of atmospheric flow fields. The above-mentioned solution describes a generalised geostrophic equilibrium, which can be expressed in terms of a three-dimensional stationary velocity vector $\mathbf{v}_{\mathbf{s t}}$ :

$$
\mathbf{v}_{\mathbf{s t}}=\frac{1}{\rho \Pi} \nabla \theta \times \nabla B .
$$

Here $\theta$ denotes the potential temperature, $\Pi$ is Ertel's potential vorticity (PV), $B$ the Bernoulli-stream function and $\rho$ the density of air. For a classical derivation in terms of the governing equations see Schär (1993). The DSI is defined as a Jacobian determinant:

$$
D S I:=\frac{1}{\rho} \frac{\partial(\theta, \Pi, B)}{\partial(x, y, z)},
$$

which locally includes the information about entropy, energy and potential vorticity and describes diabatic and nonstationary processes of the atmospheric flow field. Because of the functional dependence of the Bernoulli-stream function and the PV in the stationary energy-vorticity basic state the index in this state is exactly zero $(D S I=0)$. The oscillation around the basic state is visualised by spatial dipole structures in the horizontal plane. In this way the $D S I$ is used as a dynamical threshold parameter for precipitation processes. An application of the DSI with respect to the visualisation of storm tracks and the evolution of severe winter storms and hurricanes can be found in Weber and Névir (2008).

\subsection{Physical and geometrical interpretation of the $D S I$}

In this section it will be shown that the DSI in the nonbalanced state is proportional to the advection of the squared П. Rewriting the definition of the DSI (Eq. 2) as scalar triple product $[a \cdot(b \times c)]$ and using the stationary velocity $\mathbf{v}_{\text {st }}$ (Eq. 1), the $D S I$ can be rewritten in the following way:

$$
D S I=\frac{1}{\rho} \nabla \Pi\left(\rho \Pi \mathbf{v}_{\mathbf{s t}}\right)=\mathbf{v}_{\mathbf{s t}} \cdot \nabla\left(\frac{\Pi^{2}}{2}\right) .
$$

Under general conditions the atmospheric flow is certainly not in the energy-vorticity equilibrium, so the stationary wind becomes the real, non-balanced wind. Therefore two cases have to be distinguished:

$$
D S I=\left\{\begin{array}{l}
\mathbf{v}_{\mathbf{s t}} \cdot \nabla\left(\frac{\Pi^{2}}{2}\right)=0 \\
\mathbf{v} \cdot \nabla\left(\frac{\Pi^{2}}{2}\right) \neq 0
\end{array} .\right.
$$

In addition to the mathematical derivation a geometrical interpretation together with a discussion of the sign of the $D S I$ is given in Fig. 1. Here the isolines of the Bernoulli stream function and the PV are shown on two isentropic surfaces. In the case of vanishing DSI the isolines of the Bernoulli stream function and the PV are parallel. On the $\theta_{1}$ surface, an angle between $0-90^{\circ}$ denotes a $D S I>0$. According to Eq. 4 this implies a negative advection of the squared PV. On the $\theta_{2}$-surface, an angle between $90-180^{\circ}$ denotes a $D S I<0$, which implies a positive advection of the squared PV.

\section{Cloud types derived from satellite data}

The products "cloud classes" and "cloud coverage" derived from Meteosat-8 data are uses with a temporal resolution of $15 \mathrm{~min}$. The original resolution of the Meteosat infrared data is $3 \times 3 \mathrm{~km}^{2}$. Meteosat- 8 data are transformed into a geographic projection with an effective spatial resolution of $0.01^{\circ}$. For the correction of the sun's elevation, the cosine of the zenith distance was used. In order to determine the 
cloud classes and the cloud cover, the near-infrared channels at 0.6 and $0.8 \mu \mathrm{m}$, called VIS06 and VIS08, and the thermal infrared channel at $10 \mu \mathrm{m}$ (VIS10) from Meteosat- 8 between 06:00UTC and 18:00UTC were selected. The cloud classification from satellite data is based on the distribution of clouds in different heights (i.e. with different cloud top temperatures) and with different optical thicknesses in a bispectral histogram (Berger, 1992; Langer and Reimer, 2007). One extreme case is the cloudless surface which should be the warmest and darkest area in the satellite image and the other extreme case is the cloud top of a cumulonimbus as the coldest and brightest area. The automated classification scheme tries to find those areas and builds test classes for other cloud types and calculates the arithmetic mean and the covariance for each class (Berger, 1992). For each pixel in the satellite image the probability of membership in the different classes is tested and the pixel is assigned to the class having the highest probability (Maximum-Likelihoodmethod). From Meteosat- 8 data four cloud types in the high level are determined: cirrus spissatus, cirrus fibratus, cirrus spissatus cumulonimbogenitus and cirrostratus, grouped together in the cirrus class. The medium-high clouds are determined by two cloud types, altocumulus translucidus and altocumulus together with altostratus/nimbostratus. The low clouds are separated into six cloud classes: cumulus humilis, cumulus mediocris, cumulus/stratocumulus, cumulus congestus, stratus fractus (higher clouds not visible from the ground), cumulonimbus or nimbostratus. In fact, cumulonimbus and nimbostratus do not occur at the same time. If the nimbostratus has a cirrus layer above it, the radiation characteristics due to the satellite channels are very similar to those of cumulonimbus and a separation of the cloud type is only possible with the help of the weather type from synoptic-based stations (Xie and Arkin, 1995).

\section{Data sets}

\subsection{Precipitation data}

The Lokal-Modell (LM) of the German Weather Service (DWD) is a non-hydrostatic limited-area atmospheric prediction model with $325 \times 325$ grid points and a horizontal grid resolution of $0.0625^{\circ}(\approx 7 \mathrm{~km})$ (Doms and Schättler, 1999). Data from 2000 to 2004 were used for the evaluation of the LM hourly precipitation. Besides that, one year of LM-analysis and forecast data, from March 2004 to February 2005, was analysed. The LM-forecast data are based on 00:00 UTC runs and have the same spatial and temporal resolution as the analysis data. The LM precipitation forecast data are cumulative, from the start of the forecast run. To obtain the hourly rainfall information of this time period, the successor minus the predecessor was calculated. The following one-level-fields rainfall can be retrieved from the DWD data base: grid-scale rainfall, convective rainfall, grid-scale snowfall, convective snowfall and the total precipitation. The cumulus parametrization scheme according to Tiedtke (1989) uses a mass-flux approach to represent moist convection in the LM. In the LM cumulus convection is a sub scaled process in the LM, which is not resolved from the grid and can therefore not be simulated explicitly. To obtain the whole grid scale (stratiform) and convective precipitation, the parts of rain and snow were added to the total stratiform precipitation (TG) and the total convective precipitation (TC). The total precipitation (TP) is the sum of total convective and total stratiform precipitation.

\subsection{Input data for DSI calculation}

The DSI is evaluated on nine isentropic levels over the whole LM-domain $(325 \times 325$ grid points), for a time period of five years (2000-2004). For this purpose, successive Januaries and Julies were selected to analyse characteristic seasonal precipitation patterns. The $D S I$ is also assessed for one year, ranging from March 2004 to February 2005, with LM-analysis and forecast data in the same time frame as the precipitation data. The input data (zonal wind $\mathrm{u}[\mathrm{m} / \mathrm{s}]$, meridional wind $\mathrm{v}[\mathrm{m} / \mathrm{s}]$, temperature $\mathrm{T}[\mathrm{K}]$ and geopotential $\Phi$ $\left[\mathrm{m}^{2} / \mathrm{s}^{2}\right]$ ) are available from LM-analysis and forecast fields with a time resolution of one hour. The LM variables are interpolated on ten pressure levels (Doms and Schättler, 1999). The isentropic analysis scheme of Reimer and Scherer (1992) has been used to interpolate the LM-data from pressure levels to $\theta$-surfaces. The resulting isentropic levels are $260 \mathrm{~K}$, $280 \mathrm{~K}, 300 \mathrm{~K}, 320 \mathrm{~K}, 330 \mathrm{~K}, 340 \mathrm{~K}, 350 \mathrm{~K}, 360 \mathrm{~K}$ and $390 \mathrm{~K}$. The determinant (Eq. 2) is calculated in isentropic coordinates and PV, Bernoulli-function, gradients in $x$ - and $y$-direction were derived on $\theta$-levels. The $D S I$-fields are compared with LM precipitation (TP, TG, TC).

\subsection{Cloud data}

For the comparison between DSI and the cloud types the period February to December 2004 was analysed. The considered domain covers "Central Europe" from $5.0^{\circ} \mathrm{E} / 39.6^{\circ} \mathrm{N}$ to $20.4^{\circ} \mathrm{E} / 39.6^{\circ} \mathrm{N}$ and $20.4^{\circ} \mathrm{E} / 55.0^{\circ} \mathrm{N}$ to $5.0^{\circ} \mathrm{E} / 55.0^{\circ} \mathrm{N}$. The cloud data have the same spatial and temporal resolution as the calculated $D S I$-data, corresponding to a smaller grid of $201 \times 249$ grid points. The cloud classification derived from Meteosat- 8 data for the eleven month of the year 2004 offers the possibility to attribute a precipitation probability to special cloud types. Therefore "rain clouds" and "no rain clouds" can be distinguished. Clouds with rain are: altocumulus/nimbostratus, stratus fractus, cumulonimbus, cumulus/stratocumulus and cumulus congestus and clouds without rain are cumulus humilis, altocumulus and cumulus mediocris and the cirrus class. Only the data sets of the DSI and cloud types from Meteosat-8 between 09:00 and 16:00 UTC are used, due to the sunshine duration (Langer et al., 2008). 
(a)
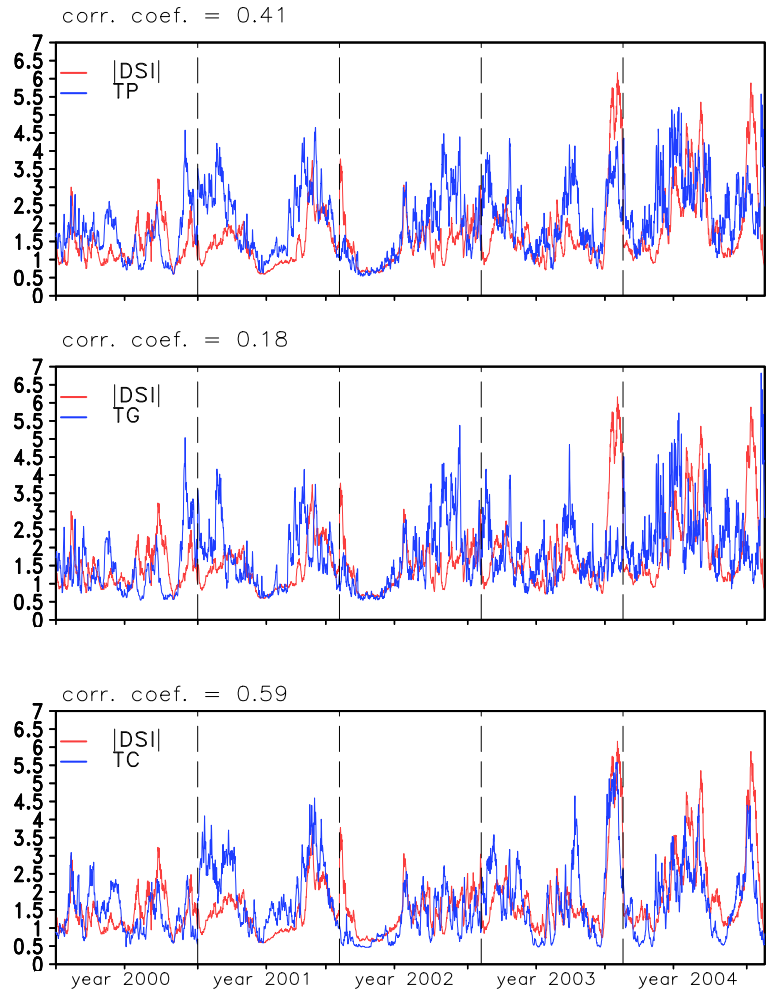

(b)
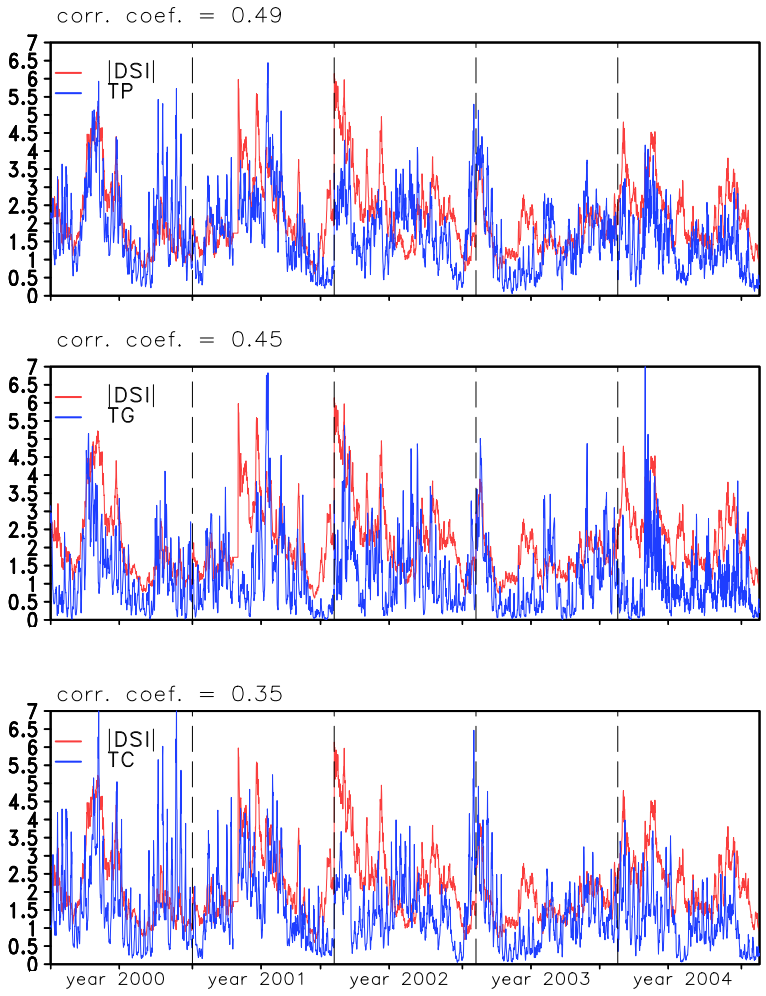

Fig. 2. Correlation coefficient between area means of $|D S I|$ and precipitation (total precipitation (TP), total stratiform (TG) and total convective precipitation (TC)) for successive Januaries (a) and Julies (b), based on hourly LM-analysis data (2000-2004, whole LM-domain of $325 \times 325$ grid points, scaled by standard deviation). The considered isentropic level is $320 \mathrm{~K}$.

\section{Results}

\subsection{Correlation between LM precipitation analysis and DSI}

In a first step, in order to show the capability of the $D S I$ for indicating dynamical precipitation processes, correlations between the area means of the absolute value of the DSI and the precipitation were calculated. Because of the dipole structure of the index, positive and negative values are averaged out. Negative $D S I$-values indicate the positive advection of $\Pi^{2}$ (Eq. 4) and vice versa. These processes are associated with the generation of precipitation. In order to avoid this cancellation, the absolute value of the $D S I$ was used. Fig. 2a,b present an example of the correlation between $|D S I|$ and total precipitation (top), total stratiform (middle) and total convective precipitation (bottom) for successive Januaries and Julies selected for the $320 \mathrm{~K}$ isentropic level. In order to facilitate the comparison both variables are scaled by the standard deviation. The highest correlation between absolute $D S I$-values and total convective precipitation is 0.59 for Januaries. In successive Julies the highest correlation is 0.49 between $|D S I|$ and total precipitation.
Contrary to the atmospheric conditions in wintertime, smallscale processes like convection and diabatic processes predominate in summer, rendering the $D S I$ and the three precipitation time series more noisy. A Fourier-analysis revealed that the noise in summer is a result of the diurnal cycle.

In order to investigate the vertical structure the correlations with different isentropic levels were investigated (Fig. 3). For successive Januaries the correlation with the total convective precipitation has a maximum at $320 \mathrm{~K}$, whereas for the total stratiform precipitation a minimal correlation exists at this height. At $340 \mathrm{~K}$ (indicated by the vertical dashed line in Fig. 3a) the mean tropopause level for the total convective precipitation can be seen. At this point the correlation coefficients decline very rapidly. A possible explanation might be, that behind a cold front stratospheric air masses reach into the troposphere and cause the descent of the tropopause height. In this area large PV values come down from the stratosphere to the troposphere and are connected with a high $D S I$-amplitude. In this sector of cold air and at the cold front convective rainfall develops, resulting in high correlation coefficients between $|D S I|$ and total convective precipitation at $320 \mathrm{~K} / 330 \mathrm{~K}$. The explanation of the weak correlation 
coefficients between $|D S I|$ and TC in the lower troposphere $(260 \mathrm{~K} / 280 \mathrm{~K})$ is, that under conditions with negative vorticity advection and cold air advection the total convective precipitation can not develop. Stratiform precipitation is often connected with nimbostratus clouds. These clouds have their mean top height at the $600 / 700 \mathrm{hPa}$ level $(\approx 300 \mathrm{~K}$ isentropic level). So the middle troposphere is very dry above the nimbostratus clouds $(320 \mathrm{~K} \approx 400 \mathrm{hPa}$ ) and the low correlation coefficients between $|D S I|$ and TG can be explained in the vicinity of the $320 \mathrm{~K}$ isentropic level. Advection of vorticity and temperature cause the generation of cyclogenetic, synoptic systems with low and medium-high clouds. The high correlation coefficient between $|D S I|$ and TG at $280 \mathrm{~K} / 300 \mathrm{~K}$ reflects synoptic systems with the associated stratiform precipitation. The distribution of the correlation coefficients between $|D S I|$ and total precipitation in successive Januaries results from the TG and TC. In the lower troposphere the stratiform part dominates and in the upper troposphere the convective part is pronounced.

In summer the correlations of all three precipitation types show a local minimum at $330 \mathrm{~K}$, and a double peak with two local maxima around $320 \mathrm{~K}$ and $350 \mathrm{~K}$. In summer convective precipitation develops mostly in warm air areas (humid and warm) in front of cold fronts. Therefore the tropopause height is very high around $360 \mathrm{~K}$ isentropic level (displayed by a dashed line in Fig. 3b). The stratospheric circulation is stable and is almost uncoupled from the tropospheric circulation, so that stratospheric air seldomly streams into the troposphere. In contrast to winter, where the PV almost is transported from the stratosphere to the troposphere, in summer the PV has to form within the troposphere by latent heat release, too. Caused by instability air parcels ascend and if the water vapour is condensed, latent heat is released. Below the heat source the vertical temperature gradient is enhanced and therefore also the static stability and potential vorticity are increased. The PV-tower and the resulting DSI-amplitude build up in the whole troposphere, which are visible for the convective precipitation between $320 \mathrm{~K}$ and $360 \mathrm{~K}$ (Fig. 3b). This behaviour is reflected by the correlation coefficients between $|D S I|$ and TC. For the stratiform precipitation the first peak at $320 \mathrm{~K}$ corresponds with synoptic systems, corresponding to the winter circulation. The second peak at $360 \mathrm{~K}$ in successive Julies (as well for successive Januaries) results from non-stationarities inside the jet level. The ageostrophic components in the delta of the frontal zone induce the cyclogenesis, which are identifiable in the $D S I$-field. Upper-level divergence induces low-level convergence with the ascent of air masses, the so-called RydScherhag effect (Scherhag, 1948). This ascent is connected with the cooling and expansion of air parcels and therefore with the generation of stratiform precipitation. In successive Julies the correlation coefficients between $|D S I|$ and the total precipitation are modulated by the stratiform precipitation at $320 \mathrm{~K}$, by the convective precipitation at $330 \mathrm{~K} / 340 \mathrm{~K}$ and again by the stratiform part of the total precipitation at the

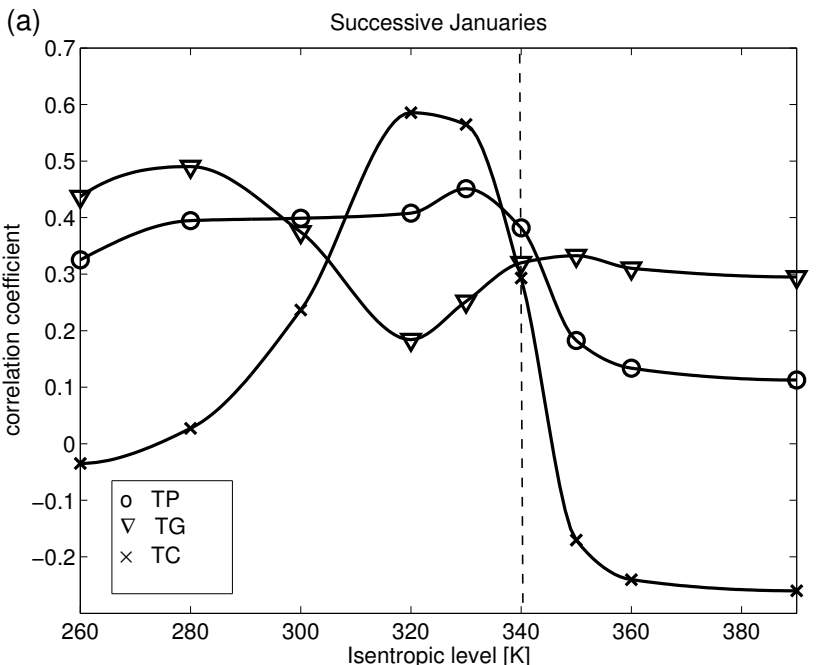

(b) Successive Julies

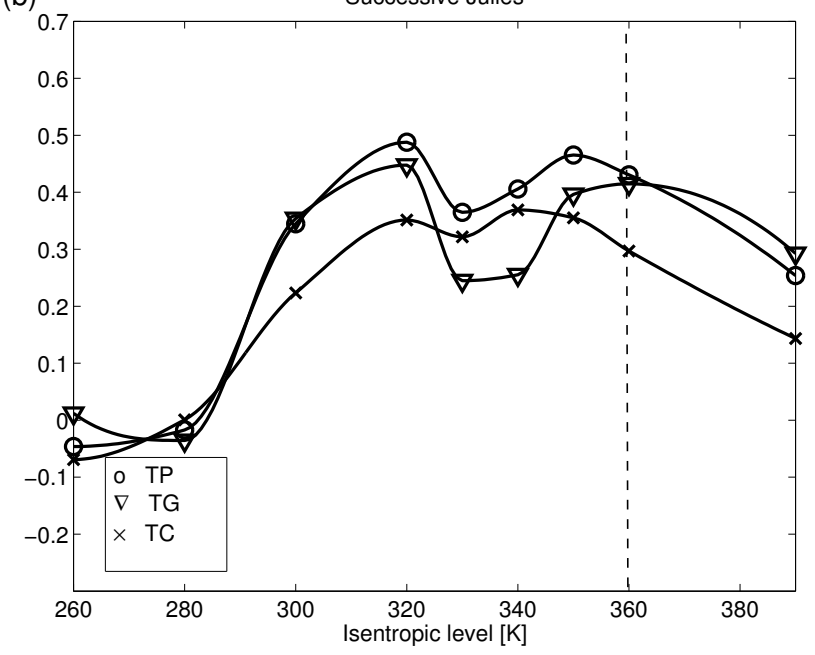

Fig. 3. Correlation coefficient between area means of $|D S I|$ on different isentropic levels $[\mathrm{K}]$ and precipitation (total precipitation (TP), total stratiform (TG) and total convective precipitation (TC)) for successive Januaries (a) and Julies (b), calculated from hourly LM-analysis data (2000-2004, whole LM-domain of 325×325 grid points).

temperature higher than $350 \mathrm{~K}$.

\subsection{Case study}

The previous subsection investigated the statistical behaviour of the $D S I$, while the following discussion demonstrates the importance of the synoptic analysis of precipitation events. Since the highest correlation between the $|D S I|$ and total the convective precipitation is found at around $340 \mathrm{~K}$ as shown in Fig. 3b, a DSI pattern is investigated at the $340 \mathrm{~K}$ isentropic level during the passage of a cold front over Germany on 21 September 2004 (Fig. 4a). The circulation pattern of the transition season in September more strongly reflects the 
(a)

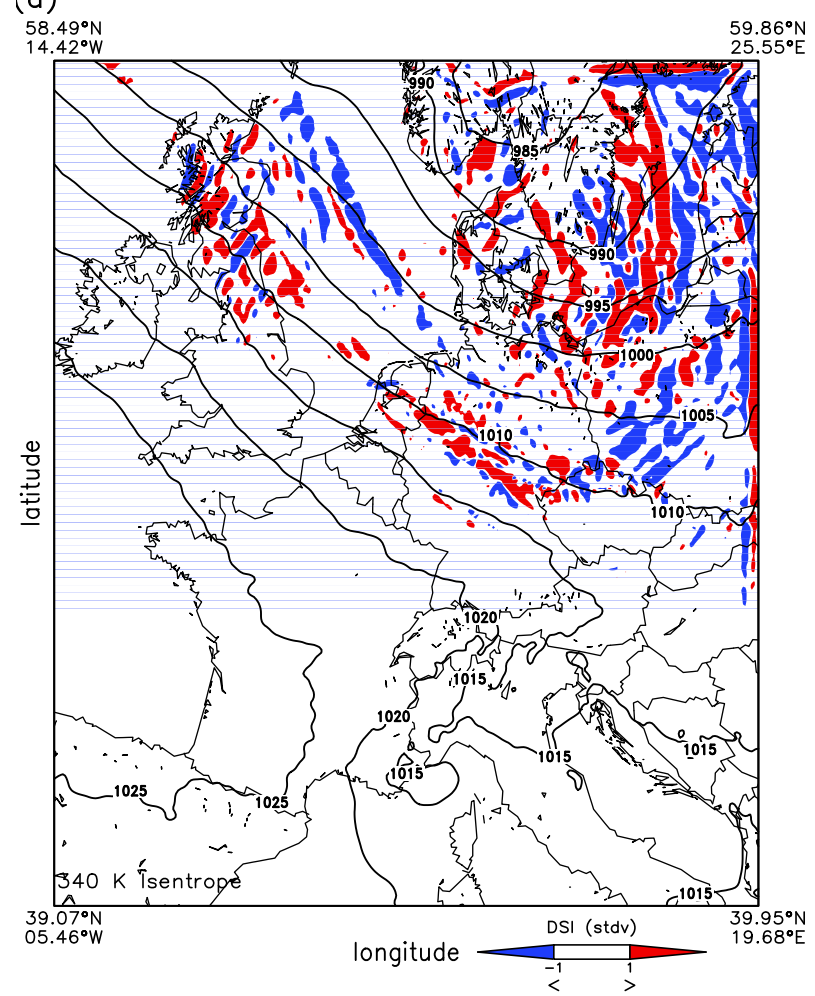

(b)

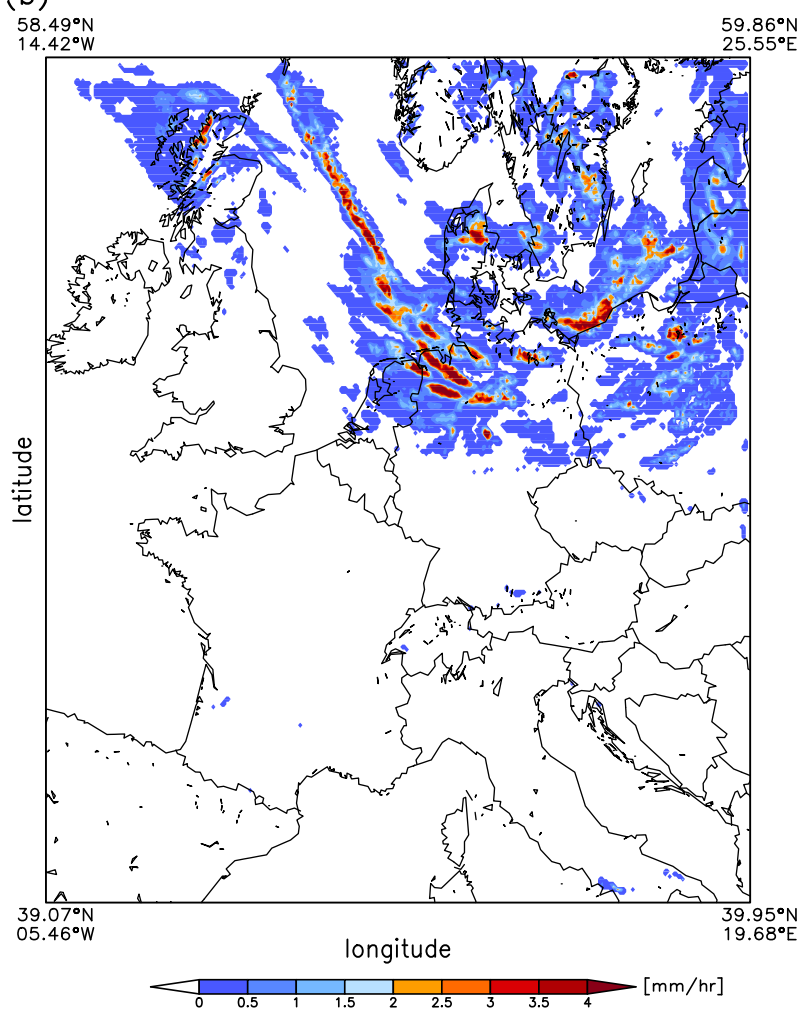

Fig. 4. Cold front on 21 September 2004 at 12:00 UTC. (a) DSI calculated from hourly LM-forecast data on $340 \mathrm{~K}$ isentrope (scaled by standard deviation). Red color indicates positive $D S I$ values and blue negative values. The solid lines show the mean sea level pressure (MSLP). The MSLP data are based on LM-analysis on 21 September 2004 at 12:00 UTC. (b) Total convective precipitation [mm/hr] on 21 September 2004 based on hourly LM-forecast data, 00:00 UTC run + (11-12h). DSI, MSLP and total convective precipitation represent the whole LM domain $(325 \times 325$ grid points $)$.

summer circulation. Also the mean sea level pressure is displayed in Fig. 4a, too. The low over Scandinavia can be seen clearly (Fig. 4a). The associated total convective precipitation is shown in Fig. 4b. It must be pointed out, that Fig. $4 \mathrm{~b}$ shows the hourly accumulated precipitation between 11:00 and 12:00 UTC, whereas the DSI in Fig. 4a displays the snapshot at 12:00 UTC. The synoptic situation was governed by the cyclone QUEEN over northern Europe. The cold front trailing behind this system passed Germany with stormy winds, moving from the Baltic Sea towards the Alps. Behind the postfrontal clearing (subsidence) rain showers developed over northern Germany and Denmark (Fig. 4b). At 12:00 UTC the cold front was above the Alps and over northern Germany a (thermic) trough line was located, which was attenuated while moving southward. Furthermore, there was an incitation of gravity waves and convective cells in the DSI-field in the north-westerly flow over the Scottish Highlands. The cold front is visible as a characteristic dipole structure of the DSI. First an exemplary interpretation of the $D S I$-pattern and the corresponding total convective precipitation field will be outlined. The quasi-stationary con- vective line over the North Sea demonstrates a good agreement between the $D S I$ and the TC. This system moved only marginally within one hour, towards the south-east with a north-westerly flow direction. The total convective precipitation also had this alignment, therefore the one hour accumulated rainfall was correctly predicted. The $D S I$-pattern over middle Germany and the Scottish Highlands shows (Fig. 4a) the trough line at 12:00 UTC moving from the north-west towards the south-east. Therefore the DSI indicates the southern boundary of the convective precipitation over Germany and the Scottish Highlands. Now the sign of the DSI shall be discussed. Writing the $D S I$ from Eq. 2 as a scalar triple product, the following form is acquired:

$$
D S I=\frac{1}{\rho} \nabla \Pi \cdot \nabla \theta \times \nabla B .
$$

By multiplying Eq. 1 with $\rho$ and the divergence $\nabla \cdot$ yields the following equation can be obtained:

$$
\nabla \cdot\left[\rho \mathbf{v}_{\mathbf{s t}}\right]=-\frac{1}{\Pi^{2}} \nabla \Pi \cdot \nabla \theta \times \nabla B .
$$


Insertion of Eq. 5 in Eq. 6 the relationship between the divergence and $D S I$ becomes apparent:

$$
\nabla \cdot\left[\rho \mathbf{v}_{\mathbf{s t}}\right]=-\frac{\rho D S I}{\Pi^{2}} .
$$

Hence, the DSI is proportional to the negative divergence, i.e. to the convergence. Positive values (Fig. 4a, red colour, for example over Germany) are connected with a weakening of the PV gradient. The cyclonic flow is also attenuated. In the upper-level at the $340 \mathrm{~K}$ isentropic level the is $D S I>0$, the convergence induced the descent of air masses and hence a weakening of the precipitation intensity. Divergent flow in the upper-level corresponds with negative $D S I$-values (blue colour) and descending motion can be attributed to the convective line over the North Sea. The cyclonic activity is amplified. A band of alternate positive and negative DSIpatterns can be seen over the Baltic Sea. This corresponds with an occlusion front, the low moved eastward. In this region weakening and amplification of the shower-like precipitation fields appeared. The DSI reflects the filament-like structure of the total convective precipitation field. In conclusion, a weakened PV gradient, associated with positive $D S I$-values, indicates a decreased cyclogenesis and therefore a lower generation of precipitation and vice versa.

\subsection{Correlation between $D S I$ and cloud types}

The former two subsections dealt with the link between $D S I$ and precipitation. In this section we concentrate on the clouds, which store the liquid water through the evaporation of water vapour from the surface. Cloud types are not used in numerical forecast models and are also no model-outputs. Only cloud coverage is determined for three different levels. However, the knowledge of cloud types is important for the forecast of precipitation, especially on the convective scale. Based on the cloud types derived from the cloud classification from Meteosat- 8 data at a resolution of $7 \mathrm{~km}$ for the month June, July and August (JJA) 2004, the cloud types were correlated with the $|D S I|$ at the $320 \mathrm{~K}$ isentropic level. For this correlation between $|D S I|$ and cloud types values from 09:00 to 16:00 UTC were selected, because the cloud classification uses the visible satellite channels. Cloud types were classified as "rain clouds" and "no rain clouds" according to Table 1. The cumulus humilis, cumulus fractus and cumulus mediocris are grouped in one class, defined as the cumulus class.

The $|D S I|$, scaled by the standard deviation, was divided into 26 classes with a bin width of 0.1 in order to generate a class related correlation for the above mentioned "rain clouds" and "no rain clouds". Fig. 5a shows a histogram of the difference of the absolute frequency of no rain clouds and rain clouds for each $|D S I|$-bin within the period JJA 2004. Clearly a $|D S I|$-threshold at the class $0.8-0.9$ can be seen, where the values change from the positive to the negative range. This result can be used to define a precipitation activ-
Table 1. Cloud types derived from Meteosat-8 and distinguished in "rain clouds" and "no rain clouds".

\begin{tabular}{ll}
\hline Clouds with rain & Clouds without rain \\
\hline altocumulus/nimbostratus & cumulus humilis \\
stratus fractus & cumulus fractus \\
cumulonimbus & cumulus mediocris \\
cumulus congestus & cirrus class \\
cumulus/stratocumulus & \\
\hline
\end{tabular}

ity index of clouds $x_{c p a}$ for each cloud type, which is defined as:

$$
x_{\text {cpa }}=1-\frac{\left(x_{0}-x_{t}\right)-\left(x_{t}-x_{\infty}\right)}{x_{\text {tot }}} .
$$

Here, $x_{0}-x_{t}$ denotes the sum of the absolute frequency for each cloud type between the $|D S I|$ values 0 and 0.9 , the $|D S I|$-threshold $x_{t}$ is $0.9, x_{t}-x_{\infty}$ is the sum of all frequencies greater than the threshold and $x_{\text {tot }}$ is the absolute frequency of the considered cloud type. With Eq. 8 a hierarchy of dynamical precipitation activity can be established, by calculating the index for each cloud type. Fig. 5b shows this new hierarchy together with the simple distribution of the relative frequency of clouds in Fig. 5c. The cumulonimbus cloud has the greatest precipitation activity, followed by the stratus fractus cloud, the cumulus/stratocumulus cloud type, the cumulus congestus cloud, the altocumulus/nimbostratus cloud type. The "no rain cloud" types such as the cumulus humilis, cumulus fractus, cumulus mediocris and especially the cirrus show a significantly lower precipitation activity. In contrast, the absolute frequency of cloud types without dynamical allocation displays Fig. 5c nearly the reverse range. This important result can be discussed using the example of the cumulonimbus cloud, which has the highest precipitation activity, but the lowest probability of occurrence. This result agrees with the findings of Peters and Christensen (2006), who showed, that rain comes in rare cloudburst rather than as a continuous drizzle. This result of the correlation between clouds and DSI gives the clouds a continuous attribution, which can be used to introduce the cloud information into numerical modelling. In a forecast-mode it is now possible to predict the precipitation activity of different cloud types.

\section{Conclusions}

The newly designed DSI field variable is a dynamic parameter, which quantitatively describes the deviation and relative distance from a stationary and adiabatic solution of the primitive equations. The $D S I$, which is calculated from spatial derivatives of basic fields of temperature, velocity and geopotential height, is related to non-stationary and diabatic atmospheric processes. Thus, the results presented here point out 
(a)

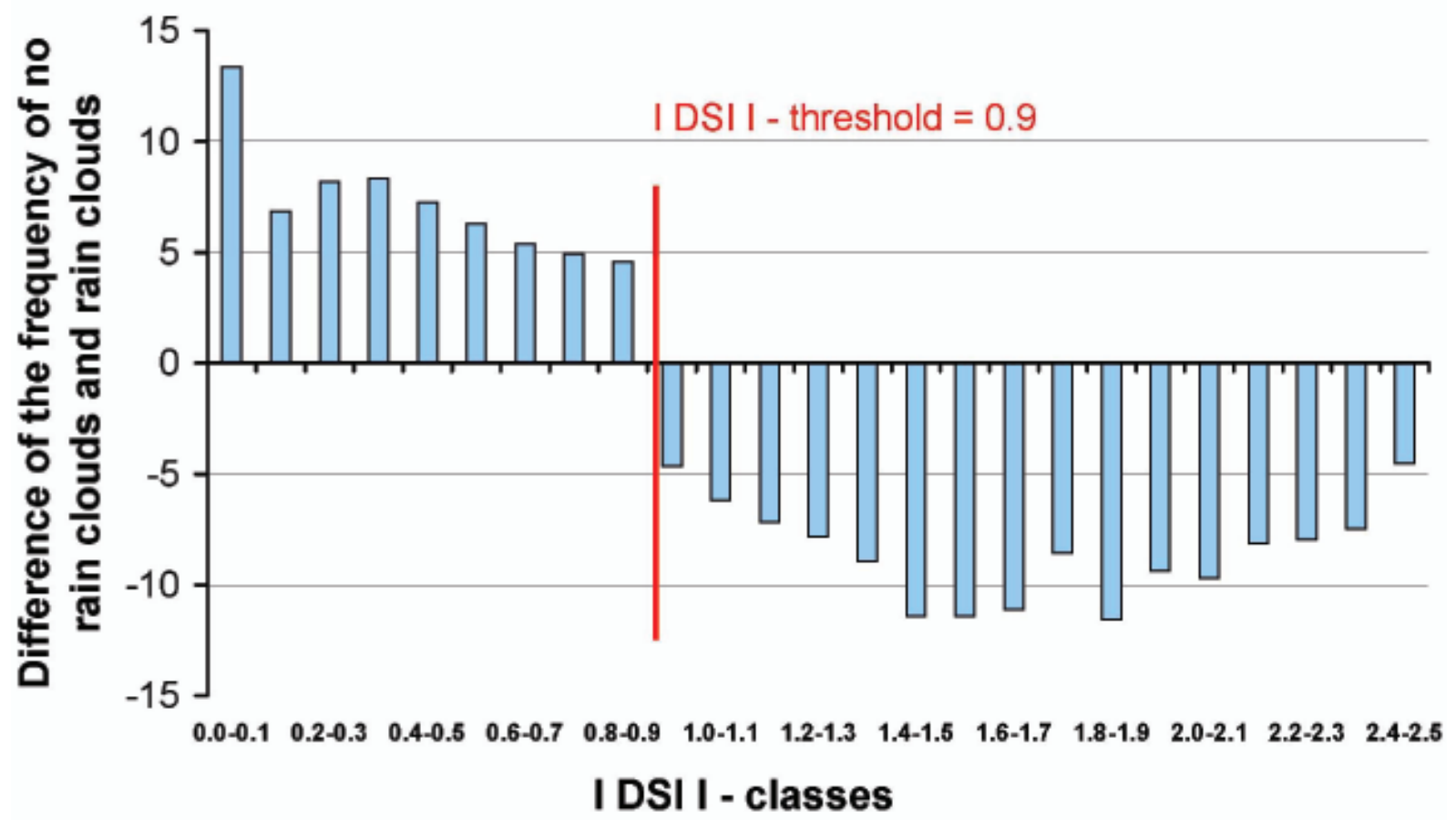

(b)

(c)
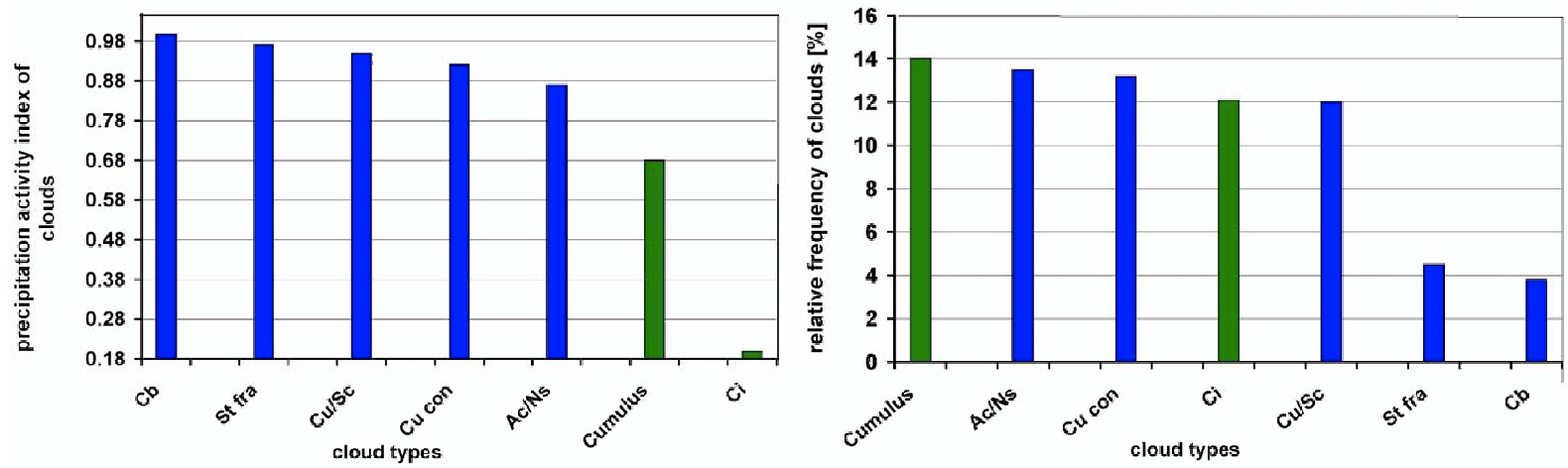

Fig. 5. (a) Normalised frequency [ $\% 00$ of the difference ("no rain clouds" minus "rain clouds") as a function of $|D S I|$ for JJA 2004 from 09:00 to 16:00 UTC. The isentropic level is $320 \mathrm{~K}$, representing the middle troposphere. (b) Precipitation activity index of clouds for different cloud types for the period JJA 2004, covering "Central Europe" calculated with Eq. 8. (c) Distribution of the related relative frequency [\%] of cloud types. The blue bars in (b) and (c) displays the "rain clouds" and the green bars the "non rain clouds" (see Table 1).

the importance of various non-balanced processes, which dynamically induce the generation of rainfall. The DSI shows a remarkably high correlation with the precipitation analysis of the LM, even without regarding the specific humidity fields. In a case study for frontal systems on the synoptic scale, the DSI reflects the filament-like structure of the mod- elled total convective precipitation pattern. With the correlation between $|D S I|$ and cloud types, derived from Meteosat8 , a threshold can be identified. By using this threshold a precipitation activity index for each cloud type has been calculated. This index clearly highlights the infrequently occurring cumulonimbus as a high precipitation active cloud type. 
An interesting study would be the analysis of the precipitation activity index for different seasons and utilising the COSMO-DE, which has a horizontal resolution of $2.8 \mathrm{~km}$ $\left(0.025^{\circ}\right)$. Besides this the correlation between $D S I$ and precipitation in a forecast mode on a smaller grid of COSMO$\mathrm{DE}$ has also to be investigated further, too. The insights gained from this project may be used for the understanding of precipitation processes and therefore this could be a cornerstone for the improvement of QPF's.

Acknowledgements. This study is part of the Priority Program SPP 1167 "Quantitative Precipitation Forecast" funded by the German Science Foundation (DFG). We would like to thank T. Schartner for the stimulated discussion and the two anonymous referees for the fruitful comments to improve our manuscript.

Edited by: S. C. Michaelides

Reviewed by: two anonymous referees

\section{References}

Banacos, P. C. and Schultz D. M.: The use of moisture flux convergence in forecasting convective initiation: historical and operational perspectives, Weather and Forecasting, 20, 351-366, 2005.

Berger, F. H.: Die Bestimmung des Einflusses von hohen Wolken auf das Strahlungsfeld und das Klima durch Analyse von NOAA AVHRR-Daten, Ph.D. Thesis, Freie Universität Berlin, Wiss. Met. Abh., Neue Folge Serie A6, 3, 1992.

Doms, G. and Schättler, U.: The nonhydrostatic limit-area model LM (Lokal-Modell) of DWD. Part 1: Scientific Documentation, Deutscher Wetterdienst, Offenbach (available from: http://www. cosmo-model.org), 1999.

Houze, R. A., Jr.: Mesoscale Convective Systems, Rev. Geophysics, 42, RG4003, doi:10.1029/2004RG000150, 2004.

Langer, I. and Reimer, E.: Separation of convective and stratiform precipitation for a precipitation analysis of the local model of the German Weather Service, Adv. Geosci., 10, 159-165, 2007.

Langer, I., Reimer, E. and Oestreich, A.: First results: Cloud classification from Meteosat data for separation of convective and stratiform precipitation, Meteorol. Zeitschrift, 17(1), 29-27, 2008.

Lovejoy, S. and Schertzer, D.: Multifractals and rain, In: New uncertainty concepts in Hydrology and Hydrological modelling, edited by: Z. W. Kundzwewics, 62-103, Cambridge Univ. Press, 1995.
Névir, P.: Ertel's vorticity theorems, the particle relabelling symmetry and the energy-vorticity theory of fluid mechanics, Meteorol. Zeitschrift, 13(6), 485-498, 2004.

Olsson, J., Niemczynomicz, J., and Berndtsson, R.: Fractal Analysis of high-resolution rainfall time series, J. Geophys. Res., 98(D12), 23 265-23 274, 1993.

Palmén, E. and Holopainen, E. O.: Divergence, vertical velocity and conversion between potential and kinetic energy in an extratropical disturbance, Geophysica, 8, 89-113, 1962.

Peters, O. and Christensen, K.: Rain viewed as relaxation events, J. Hydrol., 328, 46-55, 2006.

Reimer, E. and Scherer, B.: An operational meteorological diagnostic system for regional air pollution analysis and long term modelling, In: Air Pollution Modelling and its Application IX, edited by: H. v. Dop, and G. Kallos (Eds.), NATO Challenges of Modern Society, Kluwer Academic/Plenum Publisher, New York, 1992.

Rodriguez-Iturbe, I., Febres de Power, B., Sharifi, M. S., and Georgakos, K. P.: Chaos in rainfall, Water Resour. Res., 25(7), 1667$1675,1989$.

Rose, B. E. J. and Lin, C. A.: Precipitation from vertical motion: a statistical diagnostic scheme, Int. J. Climatol., 23, 903-919, 2003.

Schär, C.: A generalization of Bernoulli's theorem, J. Atmos. Sci., 50, 1437-1443, 1993.

Scherhag, R.: Wetteranalyse und Wetterprognose, Springer, Berlin, 1948.

Sivakumar, B.: Is a chaotic multifractal approach for rainfall possible?, Hydrol. Process., 15, 943-955, 2001.

Spar, J.: A suggested technique for quantitative precipitation forecasting, Mon. Wea. Rev., 81(8), 217-221, 1953.

Tessier, Y., Lovejoy, S., and Schertzer, D.: Universal multifractals: theory and observations for rain and cloud, J. Appl. Meteorol., 32, 223-250, 1993.

Tiedtke, M.: A comprehensive mass flux scheme for cumulus parametrization in large-scale models, Mon. Wea. Rev., 117, 1779-1800, 1989.

Weber, T. and Névir, P.: Storm tracks and cyclone development using the theoretical concept of the Dynamic State Index (DSI), Tellus A, 60(1), 1-10, doi: 10.1111/j.1600-0870.2007.00272.x, 2008.

Xie, P. and Arkin, P. A.: An intercomparison of gauge observations and satellite estimates of monthly precipitation, J. Appl. Meteorol., 34, 1143-1160, 1995. 